\title{
Flood resilience in the context of shifting patterns of risk, complexity and governance: An exploratory case study
}

\author{
Noel Johnson ${ }^{1}$ and Martina McGuinness ${ }^{1, a}$ \\ Management School, University of Sheffield, S10 1FL, United Kingdom
}

\begin{abstract}
This paper presents a case study of an industrial locale in the United Kingdom which has come together in an innovative governance structure to respond to the risk of flooding. Public and private sector bodies have joined together to establish a 'business improvement district' (BID), the sole purpose of which is to build resilience to future flooding events. More specifically, we examine the effectiveness of this strategy as a mechanism for capacity building within the small and medium sized enterprise sector. This is an important area of study as small and medium sized enterprises (SMEs) are particularly vulnerable to the negative impacts of a flood event, as they possess fewer resources than their larger counterparts leaving them with less capacity and organisational slack to respond to a major disruption. Drawing upon primary and secondary data, we identify both institutional barriers and enablers to the development of novel responses to flooding.
\end{abstract}

\section{Introduction}

Climate change research suggests that the frequency and magnitude of floods will become more common as milder, wetter winters and localised weather events become more prevalent across Europe [1] The potential costs of flood damage to the UK economy in twenty-five years have been estimated at $£ 10 \mathrm{bn}$ and flooding has been identified as a key risk facing the UK [2] requiring novel approaches [3] and new strategic partnerships [4,5].

Floods are socially constructed, that is, they are "social events in social time, disruptive to social intercourse and need to be understood in the context of social change (human and institutional adaptability)" [6]. Flood impacts are felt beyond the immediate event occurrence, with the potential for significant long-term effects across a range of stakeholders. Consequently, a full understanding of flooding is not possible without reference to the institutional context within which it emerges, and more particularly, the socio-technical water system within which it is situated. In referring to the institutional domain, we follow Scott's conceptualisation of institutions of regulative, normative and culturalcognitive elements that, together with associated activities and resources, provide stability and meaning to social life" [7]. These dimensions are formal and informal; explicit and implicit. They shape and influence governance at different levels and span concomitant inter and intra organizational boundaries, including; the regional and national (e.g. EU and UK), sectoral (public, private and third sector), industrial (manufacturing and service industries) and firm (large, medium and small) level.

\footnotetext{
a Corresponding author: m.mcguinness@sheffield.ac.uk
}

At the firm level, preparing for, and responding to the impacts of flooding demands the management of resources within and across organizational boundaries. When constrained by conflicting cultural and institutional forces this presents a complex governance and management challenge. Examples of relevant policy and regulatory frameworks include the European Floods Directive (2007/60/EC, FD, 2007) which calls for the active involvement of all interested parties (Art.10) and where public participation is seen as key [8] and the UK Civil Contingencies Act (2004) which established a framework to enable a wide range of stakeholders to be integrally involved with emergency management planning. However, there is less clarity as to how the stakeholder engagement and capacity building embedded within these policy and regulatory frameworks might best be achieved [9-11].

Organizational capacity building can demand management within and across various contextual boundaries including business sectors (public-privatevoluntary), structural boundaries (bottom-up and topdown participation), and 'hard' and 'soft' (physical and social) measures [12]. We draw upon the notions of permeable boundaries and social ecosystems from theories of 'complexity' [13-15] to explore the response of one industrial locale in the United Kingdom to the risk of flooding. Specifically, we focus on one strategy for capacity building within the small and medium sized enterprise (SME) sector - the establishment of a business improvement district (BID) for the purpose of developing flood resilience.

Although we find the BID to support interorganizational capacity building, we also identify 
organizational boundaries acting as barriers to capacity building. The paper proceeds as follows; firstly we provide a review of the relevant literature before outlining the development of the BID governance structure. Then we set out our research methods before presenting our findings and discussion. We draw some conclusions and indicate future research directions.

\section{Literature review}

Many of the risks faced by 21 st century society reflect changes within the broader risk domain and they are characterised by high levels of uncertainty, unpredictability and emergence - we live in a 'risk society' $[16,17]$. Climate change falls under this ambit, as does one of its concomitant hazards, flooding. Although the UK has some history of flooding (including major flood events in 1947 and 1953), this has not traditionally been seen as a significant societal risk. This is now changing. The nature of flooding in Britain has increased significantly over the past ten years, with extension in both scale and scope.

The autumn and early winter of 2000-01 saw the worst flooding in the UK since 1947; the 2007 floods resulted in the greatest loss of essential services since World War II; Cumbria and Aberdeenshire suffered severe flooding in 2009; and more recently the UK experienced its wettest winter for 250 years with a former Chairman of the Environment Agency, Lord Chris Smith, referring to extreme weather as "the number one challenge facing the nation" (2014). Hazards such as modern day flooding require novel response and regulation [18] and urgently, given that milder wetter winters and localised extreme weather events are likely to be an ongoing feature of both national and global climate patterns. The UK's National Risk Register (2015) highlights flood as a source of significant and widespread impact on people, business, infrastructure and essential services. Whilst business, broadly, is vulnerable to the impacts of major disruption from flooding, small and medium-sized businesses (SMEs) are particularly so as they are less likely to be prepared for a flood event in comparison to their larger counterparts, and also have fewer resources to mobilise in response [19,20].

Moreover, SMEs are a key economic driver and the backbone of the UK economy and many local communities. In 2015, they comprised $99.9 \%$ of the business population. Of the $5.4 \mathrm{~m}$ private sector businesses in the UK, $99.3 \%$ were categorised as small (0-49 employees), $\quad 0.6 \%$ medium-sized (50-249 employees) and $0.1 \%$ large $(\geq 250$ employees). Government figures (BIS, 2015) also show that the SME sector is responsible for three fifths of the employment and almost half of turnover in the UK private sector.

\subsection{Complexity}

Organisations, business communities and networks can be complex phenomena. Their interacting social, technical, economic, and political influences can challenge understanding and prediction. There is increasing recognition from range of managerial contexts including conflict resolution [22], crisis management [23], health care [24] and supply chain management [25] that traditional styles of management and the Newtonian theories upon which those styles are based, are unsuitable for managing in the twenty first century. This growing body of research favours the theories of complexity as an alternative to 'traditional' linear and reductionist styles of management. However, one researcher cautions that "complexity is not a methodology or a set of tools (although it can provide both). The theories of complexity provide a conceptual framework, a way of thinking, and a way of seeing the world" [15]. Complexity is an emerging field and has elements common to a wide variety of disciplines in both hard and social sciences. There is no one theory of complexity and numerous schools of thought have emerged within the complexity sciences. These schools have tended to be separated into three broad approaches: reductionist complexity science, soft complexity science, and complexity-based thinking [13]. Although most of the complexity science literature explicitly acknowledges the break from a Newtonian or mechanistic approach, reductionist complexity science still relies on a positivist method that emphasises universal commonalities more than idiosyncratic differences between systems [13]. Soft complexity science asserts a sharp distinction between social reality and the natural world. Therefore, any complexity theory originating in nature can be used only metaphorically to enrich our understanding of social interaction. A third approach 'complexity-based thinking' accepts the limitations to transferability implied by complexity theory in favour of a radical epistemological shift that recognises the contingent nature of all knowledge [13], in essence, "complexity-based thinking requires that we abandon the quest for exact knowledge or universal absolutes and seek instead the limitations and boundaries of our knowledge, by whatever means are appropriate for the situation at hand"[28].

How can the logic of complexity inform capacity building for flood resilience? Ashmos et al [29] proposed 'participation' as one simple rule to 'complexify' organizations. "Through decision processes that involve many decision makers, multiple informants, multiple interpretations and a broad set of information, the organization positions itself for developing the more complex responses that may be needed to succeed in a turbulent environment" (ibid, p.191). Ashmos et al focus on participation within organizations in order to succeed in responding to turbulence. We build upon this work by exploring governance structures that facilitate participation across organizational boundaries in the context of flood resilience.

\subsection{System boundaries}

Complex systems are open systems. Cilliers [30] argues that, rather than see a boundary as something that separates one thing from another, we should think of a boundary as something that constitutes that which is bounded. This shift in perspective encourages the view of 
a boundary as something which is enabling instead of something which is confining. From this viewpoint boundaries are both enabling and constraining components of a system and may be seen as an interface in constituting the system, its related systems and its environment. Consequently, boundaries are, 'more or less', permeable and enable a system to co-evolve with its environment. The notion of a social ecosystem [15] captures the system 'connectivity' and 'interdependence' implied by permeable boundaries (Figure 1).

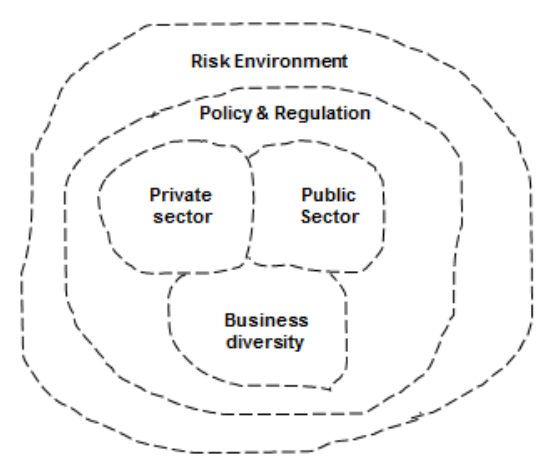

Figure 1 An organizational social ecosystem (adapted from Mitleton-Kelly, 2003)

Put simply, complex adaptive system's permeable boundaries enable the potential for what has been described as constant recursive interplay between micro and macro structures [15] and co-evolution. Individual agents can influence policy and the risk environment and vice versa. However, in human social systems, the extent to which co-evolution is enabled or constrained can be dependent on managerial intervention - enabling or blocking interaction across boundaries.

\subsection{Organizational capacity building}

The notion of capacity building has largely been used with reference to developing countries where it has been defined a process by which individual, organisations, institutions and societies develop abilities to perform functions, solve problems and set and achieve objectives [31]. UNDP [32] redefined capacity building in broader terms as the creation of an enabling environment with appropriate policy and legal frameworks, institutional development, including community participation, human resources development and strengthening of managerial systems. Capacity in flood risk management has been described as the capability of individuals, groups, institutions, authorities and of local societies as a whole, to live with and adapt to a locally specific exposure to waters and flood hazard in a sustainable way [33].

These definitions embrace the notion of 'complexity'; a world that is increasingly subject to interdependence. This changes the conceptualisation of 'capacity building' from a mechanistic resource-transfer mentality to a systemic understanding of, and approach to, change [34]. A systemic approach to flood resilience seeks to strengthen the organisational and relational capacities across organisational boundaries to create conditions that position societies more capable of coping and adapting to flood risk. Thus, capacity building must comprise tasks, strategies and methods that enable societies and their individuals to develop this capability [33]. A critical review of the capacity building literature and discourse [12] identified three interrelated themes that permeate the literature. We adapt these themes to shift the focus from development to flood risk management:

The multi-dimensional focus of capacity building, integrating macro-to micro-level dynamics as a necessary response to the systemic nature of society and change.

The interplay between 'soft' (motivational and process) and 'hard' (technical) elements of capacity, as having significant bearing on the efficacy of flood risk management initiatives. The need to create and strengthen intra and inter-sectoral partnerships as part of a systemic approach to flood risk management.

Although language such as cooperation, participation, ownership, multi-stakeholder dialogue, and democratic processes permeates the capacity-building discourse [12], there is less certainty as to whether these concepts are being practised in capacity building processes and outcomes.

\subsubsection{Integrating macro-micro level dynamics}

Macro and meso-level responsibility for introducing flood protection and mitigation policies can lie with the relevant government agencies such as the Environment Agency, and Local Planning Authorities respectively. Micro-level responsibility for the implementation of flood mitigation measures i.e. at the property level can lie with individual property owners or occupiers. Individuallevel adaptation measures are likely to be limited in the UK, partly due to relying on the state to provide full protection [35]. Another area where macro-micro level influence might be integrated is in the governance structures (boards, committees, steering groups) for initiatives concerned with building flood resilience. This might be achieved by the inclusion of macro-micro stakeholder representation with a spread of power and interest, along with democratic decision making processes. The challenge or implication remains to identify and implement ways to integrate macro-micro level dynamics elements of capacity building for effective flood resilience.

\subsubsection{Hard and soft elements of capacity building}

'Hard' and 'soft' elements of capacity building may be considered as structural and non-structural respectively [36]. Structural measures include the physical defences and protection measures designed to increase flood resistance by preventing flood water entry in to a property and flood resilience by minimising the impact of flood water on a property. Non-structural might include business continuity management (BCM) measures and adjusting and re-aligning business processes. One definition of business continuity planning explicitly highlights the need to span both hard and soft elements of capacity building: 
"Planning which identifies the organization's exposure to internal and external threats and synthesizes hard and soft assets to provide effective prevention and recovery, while maintaining competitive advantage and value system integrity" [37].

However, Crichton's [38] study of the effects of climate change on UK small businesses, found that $69 \%$ of businesses located in high flood-risk areas did not have business continuity plans in place and a similar number of organisations had no concern about the impact of flooding. The challenge or implication is to identify and implement ways to integrate hard and soft elements of capacity building for effective flood resilience. 55\% of those living in flood risk areas knew they were at risk and for these 3 out of 5 had taken some action to prepare for flooding

\subsubsection{Intra and inter-sector partnerships}

Ingirige and Amaratunga [39] note "implementing approaches to improving the resilience of societies against extreme flood events that require the participation of both public sector (national government, local government and regulatory bodies) and private sector (individual households, businesses and voluntary bodies) have not been well established". A study of the 2009 flood in Cockermouth UK describes a recovery period enabled by a successful partnership between the local borough council and the small businesses in collaboration with the chambers of trade [36]. Close collaboration between these organisations enabled flooded businesses to move into temporary premises thereby limiting the disruption experienced by those businesses. A key point in the study is how the multi-stakeholder engagement strategy enabled the local council to work with community funding agencies, emergency planners, chambers of trade, the environment agency and the whole small business community in the recovery process.

To summarise, what each of these interrelated themes has in common is the multi-level spanning of organisational/contextual boundaries, thereby embracing the interdependence and complexity of building effective and sustainable 'capacity'. But involving interested parties in flood risk management is a crucial and challenging issue. Although the implementation of the European Union Directive on the Assessment and Management of Floods (Directive 2007/60/EC) calls for the active participation of stakeholders [40], achieving stakeholder participation successfully can be a challenge [10].

\subsection{Resilience and flood resilience}

There is no single definition for resilience. Its meaning can vary across disciplines. A theme that emerges from reviews of resilience is that it is a dualnatured construct. It appears on the one hand to be an ability to absorb shocks and restore prior order, the other hand an ability to positively adapt to change and transform experiences or situations to advantage. For example, in engineering, resilience can mean the ability to absorb energy in the elastic range [42], whereas ecological resilience envisions ecosystems as constantly changing and focuses on renewal and reorganisation processes $[43,44]$. This tension can also be seen in the single, albeit wide-ranging, domain of organisation studies. Wildavsky [45] described resilience as "the capacity to cope with unanticipated dangers after they have become manifest, learning to bounce back", whereas Lengnick-Hall and Beck [46] argue resilience extends beyond 'bouncing back' and suggest it is an organisation's transformational capability comprising a complex blend of perspectives, behaviours, processes and contexts.

From a policy perspective, UK Government has defined resilience has been defined as "the ability to detect, prevent and if necessary handle disruptive challenges" (Civil Contingencies Secretariat, 2004). The term has been adopted by government to describe the way in which it would like to reduce the nation's susceptibility to major incidents of all kinds and as an integral part of community capability. This is seen as being achieved by reducing the probability of such occurrences and their likely after-effects, as well as through building institutions and structures in such a way as to minimise any possible effects of disruption upon them (Cabinet Office, 2004). The policy is holistic; embracing all sections of society from private sector business through public sector institutions to affected communities themselves. However, the challenge lies in translating resilience focussed 'policy corridors' into effective and sustainable practice at the local level. As Wilson notes [47] 'resilience is not 'made' and does not emerge out of a vacuum, but it is transferred through complex processes of policy and other exchanges between communities and wider society". Equally, path dependence creates the danger of 'lock-ins', that is barriers to effective community resilience, including structural, economic and socio-psychological lock-ins [48].

\subsubsection{Coping and adaptation}

Birkmann's [49] work on coping and adaptation processes to natural hazards and climate change captures the tension within the resilience construct in the form of coping and adaptation processes. Coping processes correspond with immediate and direct impacts and consequences. Thus coping corresponds with absorbing shocks and/or restoring a degree of prior order aspect of resilience. Coping processes might include raising floor levels, moving important items to an upper floor during a flood, or staying at home or work and waiting for the flood to recede [49]. Adaptation processes correspond with medium and long-term change, adjustment, and reorganisation. Adaptation processes for a business might include diversification to reduce or remove risk from flooding, building property on pillars or relocating elsewhere away from flood risk (ibid, p.825).

Although capacity building and resilience are two distinct constructs they may be interrelated. For example, resilience has been described as an organization's 
capacity to absorb the impact and recover from the actual occurrence of an extreme weather event [50]; and as the skill and the capacity to be robust under conditions of enormous stress and change [51]. However, commitment to building capacity for resilience may be problematic for some types of organisations. For example, SMEs have been characterised as having limited resources in the form of time, money and human capital [52,53] which may hinder capacity and resilience building processes. Figure 2 presents a conceptual/analytical framework which depicts our interpretation of Black's [12] interrelated capacity building themes in the context of flood risk management as enablers for Birkmann's [49] notion of coping and adaptation which we interpret as resilience.

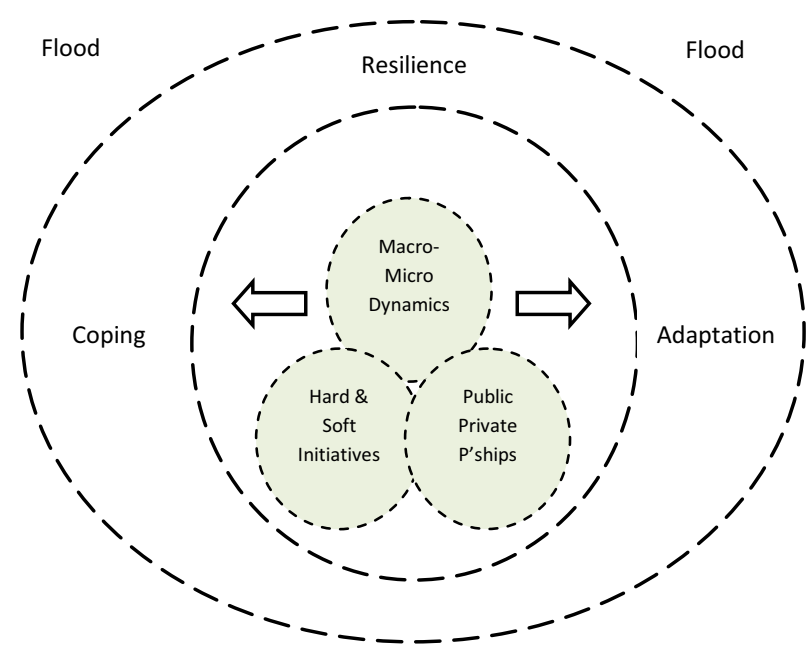

Figure 2 Interrelated capacity building themes as enablers for coping and adaptation (resilience).

\subsection{Business Improvement Districts}

A Business Improvement District (BID) is a partnership between a local authority and local businesses aimed at providing improvements to the public sphere a specific geographical area [54]. Central to any BID is public-private partnership. Whilst this structure has been in in operation across North America since the late 1960s. The transferability of this form of urban governance is remarkable. Spreading from North America, this 'travelling concept' now spans the globe [55]. This is not to say that the model is uncontentious. Critiques of this form of urban governance include concerns about their democratic deficit [56,57], limited public accountability [58], focus on profit maximisation [59] and the lack of evaluation of effectiveness and value for money [60].

This form of public-private network governance is a more recent development in UK, established under statute in 2004. This legislation created an explicit regulatory framework for any potential BID. A democratic process is a key underpinning with a ballot of the business in the specified area is conducted, under the auspices of the local authority with a majority vote (votes cast and rateable value of votes cast) needed in order for proposal to proceed. Within this defined area a levy is charged on all business rate payers in addition to the normal business rates bill. This levy is used to develop projects which will benefit businesses in the local area [61]. Although there are no restrictions on the projects or services which are the basis of a BID, there is a requirement is that it is something additional to services provided by the local authority. Under a BID, property occupiers agree to pay a levy for a maximum of five year period, after which time, the BID becomes moribund or a renewal ballot for a further five years. To date, there are more than 200 British BIDs [62]. BIDs can vary significantly in size. In the UK, the smallest consists of 62 rateable businesses and the largest has 1,400 . This highlights the flexible nature of this governance tool in terms of the significant difference in BID project scale which can be accommodated in the same type of structure. In Glasgow, Sauchiehall Street (the smallest) is a relatively small area for which the BID focus is to increase visitor numbers (both home and abroad) through concerted marketing strategies and enhancements in the local environment [63]. Bu way of contrast, Newcastle's NE1 (the largest to date) is city wide and consists of a portfolio of activities which include both capital investment projects as well as events and services [64]. The most recent survey of BIDs in the UK shows that Town Centre BIDs predominate, accounting for $86 \%$ of current projects in comparison to industrial BIDs which represent $14 \%$ of the total $(n=203)$. Marketing, security and environmental enhancements are typical BID focussed activities generally aimed at increasing visitor numbers to the locale. Much less common are BIDS which act in partnership with other bodies for the purposes of large capital investment projects.

\section{Research methods}

This paper draws upon data gathered as part of a larger inter-disciplinary project which comprises of a number of geographical case studies of flooding in the UK. The findings reported here relate to one of these project case studies, Sheffield, which suffered severe flooding in 2007. An exploratory case approach $[65,66]$ was adopted in order to gain insights into, and understanding of, businesses' response to flood events within their local, regional and national context, and particularly the behaviours of SMEs from their experience of responding to the 2007 flood event. Twenty-eight interviews were carried out in total, with participants drawn from local businesses (including those resident in the BID domain) and other key stakeholders in the BID process. Semistructured interview was the chosen method of data collection to (i) give the interviewee the opportunity to develop ideas and expand on issues which emerged (ii) allow the interviewer the opportunity to probe interviewee responses as appropriate, and thereby (iii) generate rich data which would then inspire new ideas [67]. This structure offered benefits in allowing the exploration of different stages of the flood event; from the pre-event level of normal operations and existing preparedness, through response, recovery and longer term preparedness. Initial pilot interviews were conducted by the two authors 
together and the interview schedule was adjusted and refined as a result. Qualitative analysis of the data was conducted using the software, Nvivo.

\section{Findings and discussion}

The city of Sheffield is located in the Yorkshire and the Humber region of the north of England. With a population of over 560,000 , it is the fourth largest city in England. It lies in a valley, through which the River Don and its tributaries, (the Loxley, Rivelin, Porter Brook and Sheaf) flow. Traditionally associated with heavy industry such as steel and coal mining, it suffered significant economic decline through the 1970 s and 80 s. The past twenty years have seen a range of initiatives aimed at reversing this decline including the formation of the Sheffield City Region in 2004. The aim of which is to enhance the economic output for the area. Part of the regeneration of Sheffield has happened along the River Don where a concentration of manufacturing and engineering businesses have emerged over time. Thus this area is of particular economic significance to the city of Sheffield and the wider region.

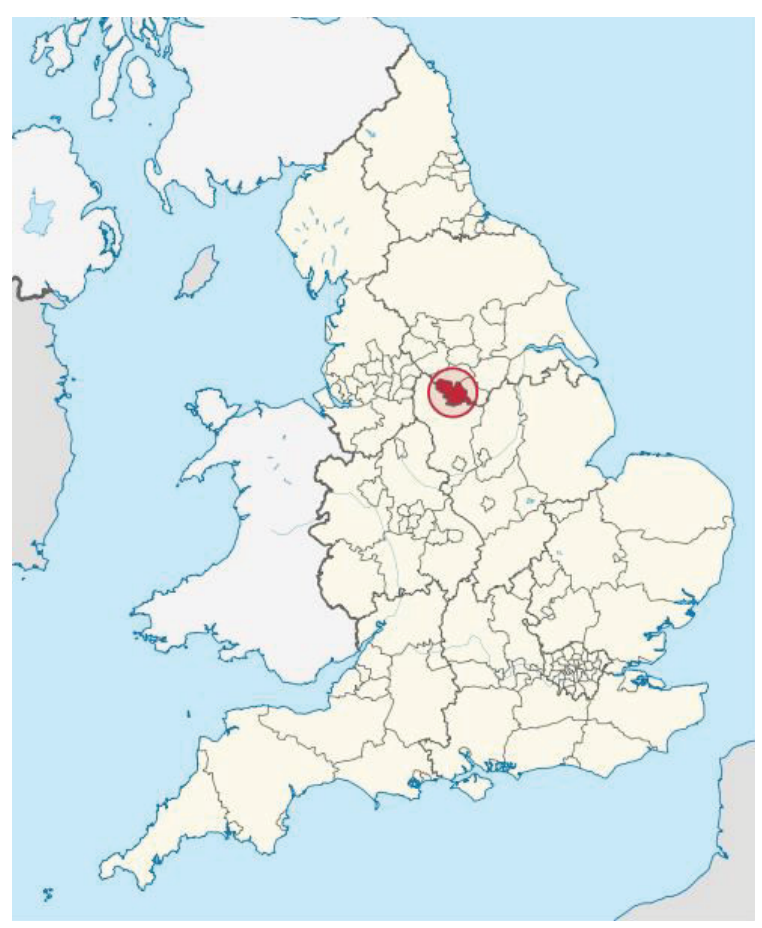

Figure 3 Map of England showing city of Sheffield (source: Wikipedia Commons)

As a result of its economic importance, our case study focuses upon the BID area which stretches alongside the Lower River Don. The locale is home to approximately 300 small and medium sized enterprises (SMEs) many of which are engineering and manufacturing firms. A severe, and unprecedented, flood event in 2007 resulted in disruption, damage and losses for many of these businesses.

As a consequence, a proposal was made to create a BID the purpose of which was solely flood defence and the aim of the project was to improve flood protection up to and including a 1 in 100 year event standard. To achieve this over 50 interventions are planned along an eight $\mathrm{km}$ stretch of river.

The Chairman of the Local Enterprise Partnership described the Lower River Don as "home to hundreds of very successful businesses and creates thousands of highly skilled jobs." He supported the creation of the BID, arguing that "local business leaders will be able to collectively take control of this problem - reducing the threat of flooding, improving the sustainability of their business community and attracting new investment to the Sheffield City Region."

One critique of BIDs has been around perceptions of democracy. Our case study shows a mixed outcome in this respect. A ballot of the affected businesses was held over a one month period at the end of 2013 and turnout was $35 \%$ of all eligible voters. Whilst the ballot turnout may seem low, and it is below the average of $47 \%$ reported for UK BIDs, it is significantly higher than recent ballots e.g. West Bromwich (17\%) and Greater Yarmouth (19\%) [68]. There was an $82 \%$ majority vote and, equally importantly, a majority was returned in terms of aggregate rateable value of businesses - of a total of $£ 10.86 \mathrm{~m}$ rateable value, $£ 10.12 \mathrm{~m}$ voted in favour of the flood defence scheme $(95 \%)$.

The structure of the BID is such that small companies with a rateable value less than $£ 12,000$ are excluded from paying towards the project, while more than $60 \%$ of businesses in the BID area pay less than $£ 2,500$ over 5 years towards the flood defences and river management. In practical terms, this means that $£ 1.4 \mathrm{~m}$ will be raised through the BID structure over a five year period. More importantly, securing this private sector finance will unlock complementary monies under the government's policy of Flood and Coastal Resilience Partnership Funding [69.70]. This policy introduced a new partnership funding approach based on cost sharing between national and local funding sources approach for flood and coastal erosion reduction projects. Therefore over $90 \%$ of the total flood defence project costs $(£ 19.04 \mathrm{~m})$ are being met by the Department for Environment, Food \& Rural Affairs (Defra) and the Environment Agency (EA). Securing this funding proved to be crucial for success given that the BID process was conceived during a period of economic downturn and austerity. Key partners acknowledged this and also highlighted the importance of a successful BID in contributing to the future economic prosperity for the BID locale, and the City Region more widely.

The Chamber of Commerce welcomed the successful BID, saying "We realise it has been a tough period for companies, so we very much appreciate this long-term commitment businesses are showing to improving the [proposed BID] area. It's a significant development, which will also see substantial financial backing from Government, to improving a key economic location in the Sheffield City Region.”

The City Council echoed this, stating "Making the city resilient to climate change is essential to the future success of our businesses. I believe this flood defence Business Improvement District - the first of its kind in the country - shows that the Council and the private 
sector can work together positively to help achieve this." (City Council, December 2013)

BIDs have been common in towns and cities in England for purposes such as urban regeneration, reducing crime, improving security and achieving 'green' management targets. However, in the wake of the UK floods in 2007 an independent review highlighted potential opportunities for businesses to work in partnership to fund local flood mitigation measures, specifically citing BIDs as one process with potential to facilitate such partnerships [19].

What can be seen from our early findings around the case study is an emergent social ecosystem. The figure below illustrates the flood defence BID structure from a systems perspective. This ecosystem's properties facilitate capacity building around flood resilience reflecting some of Black's themes.

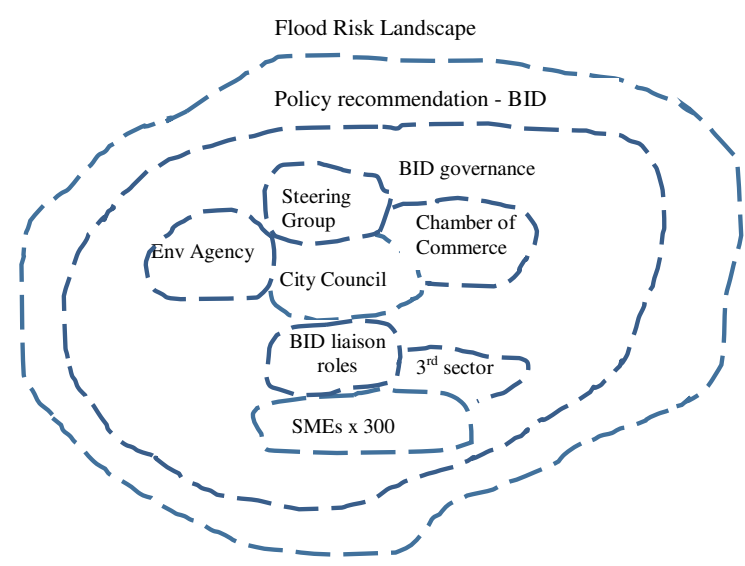

Figure 4 BID stakeholders as a social ecosystem

The first of Black's [12] themes relating to capacity is 'The multi-dimensional focus of capacity building, integrating macro- to micro-level dynamics as a necessary response to the systemic nature of society and change'. The BID process has been proposed at policy (macro) level [19] for businesses to work in partnership to fund local (micro) flood mitigation measures. One area found to be of concern for some of the BID members (SMEs) relates to who owns the flood risk. On one hand the cost of implementing flood risk management may be seen as a regional or national responsibility reflecting more of a macro approach to flood risk management. On the other hand, the high level of buy-in by local SMEs to the BID reflects a micro-level or local ownership of flood risk. The second of Black's themes suggests 'The interplay between 'soft' (motivational and process) and 'hard' (technical) elements of capacity, as having significant bearing on the efficacy of development initiatives'. The flood defence BID embraces both hard and soft elements of capacity building. Hard elements of the scheme include the physical defences such as walls and barriers, exploring the viability of maintaining lower levels of water in reservoirs to create storage capacity to accept excess water from rivers in heavy rain events, and ongoing maintenance of the river channel. Softer elements of the scheme include the ongoing education and engagement with SMEs and stakeholders to identify and manage day-to-day problems or concerns. The third theme is the need to create and strengthen intra and intersector partnerships as part of a systemic approach. A BID by definition falls squarely within this theme.

The BID structure and process does appear to have potential for capacity building for resilience according to our interpretation of Black's [12] themes. However, our preliminary research findings suggest mixed levels of support for the Flood Defence BID. One dominant area of concern relates to the impact of BIDs on democracy and what this means for accountability. A review by Hoyt and Gopal Agge [71] demonstrates that academics and practitioners have raised more questions than answers regarding the effect of BIDs on such issues as democracy and accountability: “.. the success of the BIDs in providing such services is essentially seen as the failure of the local municipal government, as well as the potential de-legitimization of the public sector" (ibid: 951). This position was echoed by one interviewee who suggested that the cost and responsibility should not lie with local businesses, arguing instead that the regulator already had a responsibility to manage and maintain the rivers: "the local businesses should not have to pay for anything. The Environment Agency has a responsibility and if they undertake their responsibilities as they should then we don't actually need any further flood risk works. Because if that river is maintained, the river banks are maintained, the river bed is maintained, in my view there are no issues so why should local businesses be getting involved in paying for additional works." If novel forms of governance emerge to fill vacuums which arise due to shortfall, or perceived shortfall, in government action, then traditional models of democratic accountability are thrown into sharp relief.

Another area which raises questions about the accountability of the BID process is the selection of members sitting on groups such as planning and 'steering groups'. Our observations suggest their make-up is weighted in favour of outright proponents of the BID along with powerful stakeholders. However, SME representation on to the groups is problematic; their limited resources (time, finance, manpower) may inhibit their engagement and participation and there is some evidence of a disengagement by some businesses that were involved in the early stages of the BID process. One solution to help overcome this bias may be the establishment of a coordinator role. This 'soft' capacity building role will help to deal with day-to-day issues during the life of the BID and act as a boundary spanner between public and private sectors.

\section{Conclusions}

Although it is still early days for the flood defence BID, it has created an innovative public-private governance structure for accessing funding reflecting shifting paradigms of flood risk ownership and management. It can also be seen as an adaptation initiative as part of a blend of coping and adaptation 
measures in response to extreme events in the context of climate change [49].

In the UK context, partnership working has emerged as a key underpinning for the management of [70,72,73] reflecting, as well as shaping, a paradigmatic shift from flood defence to flood risk management [74] and a concomitant move from centralised flood risk management strategy to a localism agenda [75-77]. The BID discussed in this paper provides some practical insights into what these shifts might mean in practices and some of the potential challenges associated.

\section{Acknowledgements}

The authors gratefully acknowledge the support of the UK's EPSRC in funding the research from which this paper is derived. Grant reference: EP/KO12770/1

\section{References}

1. Kovats, R. S. et al (2014) 'Europe ' in Barros, V. R., et al., eds., Climate Change 2014: Impacts, Adaptation, and Vulnerability. Part B: Regional Aspects. Contribution of Working Group II to the Fifth Assessment Report of the Intergovernmental Panel on Climate Change, Cambridge: Cambridge University Press, 1267-1326.

2. Cabinet Office (2015) National Risk Register of Civil Emergencies, London: Cabinet Office.

3. IPCC (2014) Climate Change 2014: Synthesis Report. Contribution of Working Groups I, II and III to the Fifth Assessment Report of the Intergovernmental Panel on Climate Change [Core Writing Team, R.K. Pachauri and L.A. Meyer (eds.)], Geneva, Switzerland: IPCC.

4. H.M. Government (2010) A Strong Britain in an Age of Uncertainty: The National Security Strategy, Cm 7953, London: HMSO.

5. H.M. Government (2015) National Security Strategy and Strategic Defence and Security Review 2015: A secure and prosperous Britain, London: HMSO.

6. Perry, R. W. (2005) 'Disasters, definitions and theory construction' in Perry, R. W. and Quarantelli, E. L., eds., What is a Disaster? New Answers to Old Questions, Xlibris/International Research Committee on Disasters, 311-324.

7. Scott, W. R. (2008) Institutions and Organizations, 3rd ed., Sage.

8. European Commission (2014) Technical Report 2014-078: Links between the Floods Directive (FD, 2007/60/EC) and Water Framework Directive (WFD, 2000/60/EC).

9. Walker, C. and Broderick, J. (2006) The Civil Contingencies Act 2004: Risk, Resilience and the Law in the United Kingdom, Oxford University Press.

10. Evers, M. (2012) Participation in Flood risk Management: An introduction and recommendations for implementation, Karlstad: University of Karlstad, Centre for Climate and Safety.
11. Albrecht, J. (2016) 'Legal framework and criteria for effectively coordinating public participation under the Floods Directive and Water Framework Directive: European requirements and German transposition', Environmental Science \& Policy, 55, Part 2, 368-375.

12. Black, L. (2003) 'Critical review of the capacitybuilding literature and discourse', Development in Practice, 13(1), 116-120.

13. Richardson, K. A. and Lissack, M. R. (2001) 'On the Status of Boundaries, both Natural and Organizational: A Complex Systems Perspective', Emergence, 3(4), 32-49.

14. Cilliers, P. (2001) 'Boundaries, hierarchies and networks in complex systems', International Journal of Innovation Management, 5(2), 135-147.

15. Mitleton-Kelly, E., ed. (2003) Complex Systems and Evolutionary Perspectives On Organisations, Emerald Group Publishing.

16. Beck, U. (1992) Risk Society, London: Sage.

17. Beck, U. (2009) World at Risk, Cambridge: Polity Press.

18. Hood, C., Rothstein, H. and Baldwin, R. (2001) The Government Of Risk, Oxford University Press.

19. Pitt, M. (2008) Learning Lessons from the 2007 Floods (The Pitt Review: Final report), London: Cabinet Office.

20. Woodman, P. and Musgrave, B. (2013) Weathering the storm - the 2013 Business Continuity Management Survey, London: Chartered Management Institute.

21. Department for Business Innovation and Skills (2015) Business Population Estimates for the UK and Regions 2015, BIS.

22. Hughes, S. H. (2004) 'Understanding Conflict in a Postmodern World ', Marquette Law Review, 4, 681690.

23. Paraskevas, A. (2006) 'Crisis management or crisis response system? A complexity science approach to organizational crises', Management Decision, 44(7), 892-907.

24. Kernick, D. (2002) 'The demise of linearity in managing health services: a call for post normal health care', Journal of Health Services Research \& Policy, 7(2).

25. Choi, T. Y., Dooley, K. J. and Rungtusanatham, M. (2001) 'Supply networks and complex adaptive systems: control versus emergence', Journal of Operations Management, 19(3), 351-366.

26. Holland, J. H. (1996) Hidden Order, Basic Books.

27. Rouse, W. B. (2000) 'Managing complexity: disease control as a complex adaptive system', Information • Knowledge • Systems Management, 2, 143-165.

28. Gilpin, D. R. and Murphy, P. J. (2008) Crisis Management in a Complex World, Oxford University Press.

29. Ashmos, D. P., Duchon, D., McDaniel, J. R. R. and Huonker, J. W. (2002) 'What a mess! Participation as a simple managerial rule to 'complexify' organizations', Journal of Management Studies, 39(2), 189-206. 
30. Cilliers, P. (2001) 'Boundaries, hierarchies and networks in complex systems', International Journal of Innovation Management, 5(2), 135-147.

31. United Nations Development Programme (1997) Capacity Development Resources Book, New York: UNDP.

32. United Nations Development Programme (2008) Capacity Development: Practice Note, New York: UNDP.

33. Nyberg, L., Mariele, E., Timm, R. and Scott, A. (2009) 'Capacity building on sustainable flood risk and water management-transnational and transdisciplinary activities in the Northsea region' in UNESCO, ed. Road Map Towards a Flood Resilient Urban Environment, Paris: UNESCO.

34. Kaplan, H. B. (1999) 'Toward an understanding of resilience: a critical review of definitions and models' in Glantz, M. D. and Johnsoton, J. L., eds., Resilience and Development, Springer Science + Business Media LLC, 17-85.

35. Harries, T. and Penning-Rowsell, E. (2011) 'Victim pressure, institutional inertia and climate change adaptation: The case of flood risk', Global Environmental Change, 21(1), 188-197.

36. Wedawatta, G., Ingirige, B. and Proverbs, D. (2014) 'Small businesses and flood impacts: the case of the 2009 flood event in Cockermouth', Journal of Flood Risk Management, 7(1), 42-53.

37. Herbane, B., Elliott, D. and Swartz, E. (1997) 'Contingency and continua: achieving excellence through business continuity planning', Business Horizons, 40(6), 19-25.

38. Crichton, D. (2006) Climate Change and its effects on Small Businesses in the UK, AXA Insurance UK plc.

39. Ingirige, B. and Amarantunga, R. (2013) Minimising Flood Risk Accumulation through Effective Private and Public Sector Engagement, Geneva: UNISDR.

40. Buchecker, M., Menzel, S. and Home, R. (2013) 'How much does participatory flood management contribute to stakeholders' social capacity building? Empirical findings based on a triangulation of three evaluation approaches', Nat. Hazards Earth Syst. Sci., 13(6), 1427-1444.

41. Evers, M. (2012) Participation in Flood risk Management: An introduction and recommendations for implementation, Karlstad: University of Karlstad, Centre for Climate and Safety.

42. Pytel, A. and Kiusalaas, J. (2003) Mechanics of Materials, Pacific Grove, CA: Thomson.

43. Holling, C. S. (1973) 'Resilience and Stability of Ecological Systems', Annual Review of Ecology and Systematics, 4, 1-23

44. Walker, B., Holling, C. S., Carpenter, S. R. and Kinzig, A. P. (2004) 'Resilience, Adaptability and Transformability in Social-ecological Systems', Ecology and Society, 9(2) art. 5.

45. Wildavsky, A. (1988) Searching for Safety, New Jersey: Transaction Publishers.

46. Lengnick-Hall, C. A. and Beck, T. E. (2005) 'Adaptive Fit Versus Robust Transformation: How
Organizations Respond to Environmental Change', Journal of Management, 31(5), 738-757.

47. Wilson, G. A. (2013) 'Community resilience, policy corridors and the policy challenge', Land Use Policy, 31(0), 298-310.

48. Wilson, G. A. (2014) 'Community resilience: Path dependency, lock-in effects and transitional ruptures', Journal of Environmental Planning and Management, 57(1), 1-26.

49. Birkmann, J. (2011) 'First- and second-order adaptation to natural hazards and extreme events in the context of climate change', Natural Hazards, 58(2), 811-840.

50. Linnenluecke, M. K., Griffiths, A. and Winn, M. (2012) 'Extreme Weather Events and the Critical Importance of Anticipatory Adaptation and Organizational Resilience in Responding to Impacts', Business Strategy and the Environment, 21(1), 1732.

51. Coutu, D. L. (2002) 'How resilience works', Harvard Business Review, 5, 46-55.

52. Van Gils, A. (2005) 'Management and Governance in Dutch SMEs', European Management Journal, 23(5), 583.

53. Sullivan-Taylor, B. and Branicki, L. (2011) 'Creating resilient SMEs: why one size might not fit all', International Journal of Production Research, 49(18), 5565-5579.

54. Sandford, M. (2013) Business Improvement Districts, London: House of Commons Library.

55. Peyroux, E., Pütz, R. and Glasze, G. (2012) 'Business Improvement Districts (BIDs): The internationalization and contextualization of a 'travelling concept", European Urban and Regional Studies, 19(2), 111-120.

56. Hoyt, L. (2005) 'Planning through compulsory commercial clubs: Business Improvement Districts', Economic Affairs, 25(4), 24-27.

57. Morçöl, G. and Zimmermann, U. (2006) 'Metropolitan Governance and Business Improvement Districts', International Journal of Public Administration, 29(1-3), 5-29.

58. Lewis, N. M. (2010) 'Grappling with governance: The emergence of business improvement districts in a national capital', Urban Affairs Review, 46(2), 180217.

59. Cook, I. R. (2009) 'Private sector involvement in urban governance: The case of Business Improvement Districts and Town Centre Management partnerships in England', Geoforum, 40(5), 930-940.

60. Donaghy, M., Findlay, A. and Sparks, L. (2013) 'The evaluation of Business Improvement Districts: Questions and issues from the Scottish experience', Local Economy, 28(5), 471-487.

61. UK Government, Guidance on Business Improvement Districts, available at https://www.gov.uk/guidance/businessimprovement-districts [accessed 29 February 2016]. 
62. British BIDS, available at http://www.britishbids.info [accessed 29 February 2016].

63. Glasgow Chamber of Commerce, http://www.glasgowchamberofcommerce.com/policy -campaigns/economic- development/sauchiehallstreet-business-improvement-district/ [accessed 29 February 2016]

64. NE1 Business Improvement District Company, http://www.newcastlene1ltd.com/ [accessed 29 February 2016].

65. Denzin, N. K. and Lincoln, Y. S., eds. (2003) The Landscape of Qualitative Research, 2nd ed., London: Sage.

66. Yin, R. K. (2013) Case Study Research: Design and Methods, 5th ed., London: Sage.

67. Siggelkow, N. (2007) 'Persuasion with case studies', Academy of Management Journal, 50(1), 20-24.

68. British BIDs (2015) Nationwide BID Survey 2015, British BIDs.

69. Defra (2011) Flood and Coastal Resilience Partnership Funding, London: Defra.

70. Defra (2012) Principles for Implementing Flood and Coastal Resilience Funding Partnerships, Bristol: Environment Agency.

71. Hoyt, L. and Gopal-Agge, D. (2007) 'The Business Improvement District Model: A Balanced Review of Contemporary Debates', Geography Compass, 1(4), 946-958.

72. Defra (2012) Principles for Implementing Flood and Coastal Resilience Funding Partnerships, Bristol: Environment Agency.

73. National Audit Office (2014) Strategic Flood Risk Management, London: Stationery Office.

74. Public Accounts Committee (2015) Strategic Flood Risk Management, London: HMSO.

75. Butler, C. and Pidgeon, N. (2011) 'From 'Flood Defence' to 'Flood Risk Management': Exploring Governance, Responsibility, and Blame', Environment and Planning C: Government and Policy, 29(3), 533-547.

76. Johnson, C., Penning-Rowsell, E. and Parker, D. (2007) 'Natural and imposed injustices: the challenges in implementing 'fair' flood risk management policy in England', Geographical Journal, 173(4), 374-390.

77. Thaler, T. and Priest, S. (2014) 'Partnership funding in flood risk management: new localism debate and policy in England', Area, 46(4), 418-425.

78. Begg, C., Walker, G. and Kuhlicke, C. (2015) 'Localism and flood risk management in England: the creation of new inequalities?', Environment and Planning C: Government and Policy, 33(4), 685-702. 